\title{
FUNCTIONS OF PHRASEOLOGICAL UNITS IN DETECTIVE PROSE OF B. AKUNIN
}

\author{
Tatyana V. Safonova \\ Tula State Lev Tolstoy Pedagogical University, Tula, Russia
}

\begin{abstract}
The author considers the problem of stylistic functions of linguistic units in modern Russian prose works through analyzing phraseological units in the detectives of B. Akunin. The article presents the most frequent types of phraseological units (idioms, set phrases, proverbs, sayings, popular expressions and other types of clichéd utterances) as representation of a personal literary style of this author. The research results point to their stylistic variety with high literary, colloquial, low colloquial, and slang units among them. The major types of phraseological unit conversion are distinguished as a prove of the writer's personal style, including, complete deformation of a component composition of a set phrase, reduction of the lexical length of phraseological units (implication), distribution of any component composition of the unit (explication), combining two or more phraseological units into a single set expression (contamination), replacement of a component in the composition of phraseological units with words of general literary layers (lexical variation), etc. The stylistic functions of all phraseological units under study are interpreted as retro-representation of the language of a certain time period, stylistic imitation of the communicative tone of oral speech, verbal characteristics of the characters who are referred to various social groups, and creation of humorous tone of the story. A comprehensive description of phraseological units used in modern fiction has revealed their artistic and stylistic potential.
\end{abstract}

Key words: vocabulary, phraseology, phraseological unit, set phrase, detective prose, variability, function, B. Akunin.

Citation. Safonova T.V. Functions of Phraseological Units in Detective Prose of B. Akunin. Vestnik Volgogradskogo gosudarstvennogo universiteta. Seriya 2. Yazykoznanie [Science Journal of Volgograd State University. Linguistics], 2019, vol. 18, no. 3, pp. 130-139. (in Russian). DOI: https://doi.org/10.15688/jvolsu2.2019.3.10

УДК 81 ' $42: 821.161 .1$

Дата поступления статьи: 14.01.2019

ББК 81.055.1-36

Дата принятия статьи: 29.05.2019

\section{ФУНКЦИОНИРОВАНИЕ ФРАЗЕОЛОГИЧЕСКИХ ЕДИНИЦ В ДЕТЕКТИВНОЙ ПРОЗЕ Б. АКУНИНА}

\author{
Татьяна Владимировна Сафонова \\ Тульский государственный педагогический университет им. Л.Н. Толстого, г. Тула, Россия
}

\begin{abstract}
Аннотация. Автор статьи обращается к некоторым проблемам функционирования языковой системы в произведениях современной художественной литературы. В качестве объекта анализа избраны фразеологические единицы русского языка. Материалом для исследования послужили произведения Б. Акунина, созданные в жанре детектива. В статье охарактеризованы наиболее частотные типы фразеологических единац (идиомы, устойчивые фразы, пословицы, поговорки, крылатые выражения и другие клишированные ㄱ высказывания), функционирующих в художественном дискурсе писателя. Показано их стилистическое разюे нообразие: обнаружены книжные, разговорные, просторечные, жаргонные фразеологические единицы. Выделены актуальные для идиостиля писателя способы преобразования фразеологизмов: полная деформация компонентного состава устойчивых оборотов, сокращение лексической протяженности фразеологизма, 웅 распространение компонентного состава единицы, объединение двух и более фразеологизмов в единый устойчивый оборот, замена компонентного состава фразеологизма словами свободного употребления и др. () Определены стилистические функции фразеологического материала, использованного Б. Акуниным в де-
\end{abstract}


тективах: воспроизведение языка изображаемой эпохи, в том числе передача оттенков разговорной речи, речевая характеристика персонажей, относящихся к разным социальным слоям, создание юмористического контекста. Комплексное описание фразеологизмов, употребленных в современной беллетристике, позволило выявить их художественный потенциал.

Ключевые слова: лексика, фразеология, фразеологическая единица, устойчивая фраза, детективная проза, варьирование, функционирование, Б. Акунин.

Цитирование. Сафонова Т. В. Функционирование фразеологических единиц в детективной прозе Б. Акунина // Вестник Волгоградского государственного университета. Серия 2, Языкознание. - 2019. T. 18, № 3. - C. 130-139. - DOI: https://doi.org/10.15688/jvolsu2.2019.3.10

\section{Введение}

В литературе Новейшего времени особое место занимает детективная проза. Ее востребованность в художественной практике постмодернизма определяется как внутренней природой данного жанра, так и спецификой современной читательской аудитории.

Детективу в его классическом понимании свойственны стереотипность структуры (завязка - преступление; кульминация - расследование; развязка - разоблачение преступника); наличие рациональных способов решения детективной загадки, доступных читателю, и интересных для него образов сыщика и преступника; отсутствие пространных описаний, литературных отступлений; динамичный и интригующий сюжет [Марусенко, Скребцова, 2013]. Основная, развлекательная, функция детектива определяет его принадлежность к так называемой массовой (популярной) литературе, целевая аудитория которой - читатель, стремящийся погрузиться в увлекательный и достаточно легкий сюжет, нежели разбираться в хитросплетениях человеческих судеб и философских размышлениях авторов классических произведений. Однако современный читатель становится все более искушенным, все труднее его заинтересовать, удивить. Стремясь максимально расширить потенциальную аудиторию, писатели-постмодернисты раздвигают канонические рамки детективного жанра, трансформируют общепринятую жанровую модель, выходя за горизонты читательских ожиданий.

Наиболее ярко данная тенденция проявляется в творчестве Б. Акунина. Элитарный детектив - так определяют жанр прозы Б. Акунина многие критики и литературоведы (см., например: [Снигирева, Подчиненов, Снигирев, 2017]), выделяя следующие особенности «но- вого дискурса» писателя: «синтез элементов массовой литературы (клишированность, формульность) с постмодернистскими приемами (интертекстуальность, ирония, пародийность, игровые контаминации с жанровыми схемами)» [Осьмухина, 2016, с. 133], реализация принципа «двойного кодирования», под которым подразумевается своеобразная «модель чтения» (совокупность норм, правил трактовки произведения), позволяющая адресовать детектив широкому кругу читателей; «достоверность воссоздания языковых реалий изображаемой эпохи», «повышенная семиотическая нагрузка текстов» [Амусин, 2009, с. 5].

Изысканность стиля детективов Б. Акунина, аутентичность языку эпохи, смысловая насыщенность во многом достигаются посредством широкого обращения к фразеологическим ресурсам языка. Однако лингвистическое изучение фразеологической составляющей дискурса Б. Акунина только начинается: к проблеме использования в прозе писателя фразеомоделей с семантикой обусловленности обращалась С.С. Сафонова [Сафонова, 2008], вопросу трансформации фразеологических единиц в аспекте языковой стратегии массовой литературы на материале цикла «Нефритовые четки» посвящено исследование Е.Н. Ермаковой и М.В. Прокоповой [Ермакова, Прокопова, 2013], специфика употребления фразеологизмов в произведениях писателя рассматривалась также Н.И. Максимовой и Л.Н. Корниловой на материале «Кладбищенских историй» [Максимова, Корнилова, 2018]. Дальнейшее исследование фразеологии прозы Б. Акунина, на наш взгляд, остается весьма актуальным, поскольку позволяет внести определенный вклад в разработку приоритетных задач современной лингвистики: выявление направлений развития фразеологической системы, описание специ- 


\section{РАЗВИТИЕ И ФУНКЦИОНИРОВАНИЕ РУССКОГО ЯЗЫКА}

фики языка художественных произведений Новейшего времени, изучение феномена языковой личности и др.

Цель данной работы заключается в описании и систематизации фразеологизмов, функционирующих в детективной прозе Б. Акунина, что предполагает установление частотных типов устойчивых единиц, их характеристику с точки зрения синтаксической модели и стилистической окраски, выявление продуктивных способов преобразования фразеологизмов, определение их стилеобразующей функции. Данной целью обусловлено широкое обращение к иллюстративному материалу, базой для которого послужили трилогия «Провинциальный детектив» и цикл «Приключения магистра».

\section{Типы фразеологизмов, функционирующих в детективах Б. Акунина}

В исследуемых произведениях представлены устойчивые единицы следующих типов (подробно о разграничении этих типов см.: [Бондаренко, 2011]): 1) собственно фраземы: сломя голову, ни жив ни мертв, курам на смех, с глазу на глаз, сойти с рук, наломать дров, ни свет ни заря, ни сном ни духом, семи пядей во лбу, одного поля ягода, приило в голову, перегнуть палку и др.; 2) устойчивые фразы (пословицы, поговорки, афоризмы, клишированные выражения): Рука руку моет; Камня на камне не оставит; 3 а морем телушка полушка, да рубль перевоз; Дареному коню в зубы не смотрят; Мал золотник да дорог; Все хорошо, что хорошо кончается; Рыба с головы гниет; Брань на вороту не виснет; Вот бог, а вот порог; Лучше меньше, да лучше и др.

С точки зрения функционально-стилистической принадлежности наиболее частотными являются разговорные фразеологиз$\boldsymbol{\mu \boldsymbol { b }}$ (98 из 214 зарегистированных): как рыба в воде, скатертью дорога, нем как рыба, кусок в горло не лезет, лиха беда начало, ума не приложу, держать ухо востро, утро вечера мудренее, ставить палки в колеса, уносить ноги, родиться в рубашке, вить веревки, выйти сухим из воды; а также просторечные (54 единицы): хоть волком вой, в омут с головой, метр с кеп- кой, на козе не объедешь, не бери в голову, лезть на рожон; реже встречаются жаргонизмы (32 единицы): взять на $\phi y-\phi y$, слить по безналу, варить бабки, гнать туфmy, поехали мозги, повело в глюки, полоскать капусту, поехала крыша и др.; книжные выражения (30 единиц): Все в руце Божьей, быть или не быть, троянский конь, парит на облацех, А завтра - иельй мир, канули в Лету, гордиев узел.

\section{Способы модификации фразеологических единиц}

Отличительная черта идиостиля писателя - частое обращение к фразеологическим единицам (далее - ФЕ) как в их исходной, словарной форме, так и в преобразованном виде. Ср.: «Образность и высокая литературность языка прозы Б. Акунина обеспечивается не только свойственной ей интертекстуальностью - насыщенностью цитатами и отсылками к известным текстам, но и активным использованием переосмысленных и окказиональных фразеологических единиц» [Ермакова, Прокопова, 2013, с. 273].

Способы модификаций ФЕ в текстах Б. Акунина разнообразны и отражают практически весь преобразовательный потенциал фразеологии, охарактеризованный в лингвистике (см., например: [Бондаренко, 2011; Мокиенко, 2012]).

Полная деформация - употребление отдельных компонентов ФЕ в качестве смыслового центра фразы, структурно отличающейся от исходной:

(1) Эх, несчастные люмпены. Щепки, отлетевшие от топоров рыночных лесорубов (Внеклассное чтение, с. 59);

(2) Слыхал, что с любопытной Варварой приключилось (Внеклассное чтение, с. 125);

(3) Давайте только факты, аргументы потом (Внеклассное чтение, с. 263);

(4) Какое из этих двух зол меньшее - очевидно (Внеклассное чтение, с. 246);

(5) «Коля, заказывай музыку - Влад Соловьев исполнит» (Алтын-толобас, с. 193);

(6) Худшая беда у них тут - не дураки и дороги, а тотальное хамство (Сокол и Ласточка, с. 39);

(7) Что и у других наших висяков по богатым, которые больше не плачуг (Внеклассное чтение, с. 103). 
T.B. Сафонова. Функционирование фразеологических единиц в детективной прозе Б. Акунина

Экспликация - расширение компонентного состава $Ф Е$ :

(8) ...Грести бабки совковой лопатой (Алтынтолобас, с. 193);

(9) Жизненная мельница все перемелет, была мука, а останется одна мука (Алтын-толобас, с. 125);

(10) Ключевая пословица москвича: не имей сто рублей (все равно не деньги), а имей сто друзей $(\Phi \mathrm{M}$, т. 1, c. 81$)$;

(11) ...Запускать слона в посудную лавку (Пелагия и черный монах, с. 83);

(12) ...Отправиться за сотни верст киселя хлебать (Внеклассное чтение, с. 560);

(13) Дело медлилось за малым (Внеклассное чтение, с. 55);

(14) Мал да удал, везде побывал, все повидал (Внеклассное чтение, с. 75).

Контаминация - объединение ФЕ, частей (компонентов) двух и более фразеологизмов в одну единицу:

(15) О, великий и могучий, сам черт в тебе ногу сломит (Внеклассное чтение, с. 365);

(16) Понадеялся на справную охрану или русский авось - пеняй на себя (Пелагия и белый бульдог, с. 158);

(17) Двум смертям не бывать, а под лежачий камень - сами знаете (Пелагия и красный петух, с. 289);

(18) Не посыпаем голову пеплом, а фиксируемся на позитиве (Алтын-толобас, с. 125).

Лексическое варьирование - замена одного или нескольких компонентов в составе ФЕ словами свободного употребления: c. 192);

(19) Долг платежом зелен (Алтын-толобас,

(20) Дело пахнет крематорием (Алтын-толобас, с. 246);

(21) Всякой плоти по паре (Пелагия и красный петух, с. 90);

(22) Ахиллесов каблук (Пелагия и красный пеTyx, c. 133);

(23) Этакого прозаика на мякине не проведешь (Пелагия и черный монах, с. 67);

(24) Волкова ноги кормят (Внеклассное чтение, с. 233).

Импликация - сокращение компонентного состава ФЕ:

(25) Но, как говорится, бодливой корове (Внеклассное чтение, с. 445);
(26) Око за око (Пелагия и красный петух, с. 352);

(27) Сколько веревочке не виться (Пелагия и красный петух, с. 352);

(28) «Да-с, на всякого мудреца»,- признался Порфирий Петрович (ФМ, т. 1, с. 117);

(29) На ловца и зверь (ФМ, т. 2, с. 271);

(30) Но игра стоит... (Алтын-толобас, с. 112);

(31) С мужчинами так и надо. Знаете, бисер перед свиньями (Внеклассное чтение, с. 204);

(32) Вот уж воистину: устами младенца (Внеклассное чтение, с. 89).

Вычленение компонентов из состава ФЕ, функционирующих на правах самостоятельного фраземного знака или лексемы:

(33) ...Пройти огонь с водой (Пелагия и черный монах, с. 407);

(34) Это бы еще ладно, но ложкой дегтя было то, что подослала денежную клиентку все та же Алтын (Внеклассное чтение, с. 22);

(35) Дай Бог, своих, родных уберечь, а чужую паству, да еще из паршивых овец состоящую, мне ненадобно (Пелагия и черный монах, с. 207);

(36) Еще раз о быке и Юпитере (ФМ, т. 1, с. 73);

(37) Мы за гуж беремся (Пелагия и белый бульдог, с. 165).

Экспликация внутренней формы раскрытие посредством контекста образного представления, ситуации, послужившей основой для создания устойчивой единицы:

(38) Верховой боярин подъехал ближе, встал подле арапа. Теперь можно было разглядеть и лицо: резкие, сухие черты, нос с горбинкой, а брови при седой бороде черные. По всему видно, большой важности человек. Корнелиус покосился на вельможу. Кланяться, lomati schapku или нет? По воинскому уставу на учениях необязательно. Ну, раз необязательно - так и нечего (Алтын-толобас, с. 124);

(39) Простонародье глазеет, как баре безо всякого смысла шпацируют по аллее взад и вперед, потешается. Даже новые словечки появились: «лодеря гонять» и «лодерничать (Внеклассное чтение, с. 444).

Авторская этимология - раскрытие внутренней формы с опорой не на научное, общеязыковое осмысление, а индивидуальное восприятие, что часто обусловлено содержанием текста:

(40) Поди-ка, возьми его с поличным. Чуть что - раз, и концы в воду. Кстати сказать, это про 


\section{РАЗВИТИЕ И ФУНКЦИОНИРОВАНИЕ РУССКОГО ЯЗЫКА}

них, «разинцев», поговорка придумана, только остальному народу невдомек. «Концами» называют добычу. А вода - вон она, за бортом плещется. Запалился - кидай «концы» в воду, и нипочем не докажут, Река-матушка всё спрячет (Внеклассное чтение, с. 22);

(41) - Я леплю горбатого? - переспросил Фандорин, сделав обиженное лицо. <...> Интересна этимология выражения про «горбатого». Почти не вызывает сомнения, что оно недавнего происхождения и связано с Михаилом Горбачевым, который у русских заработал репутацию болтуна и обманщика. Надо будет потом записать (Алтынтолобас, с. 124).

Окказиональные ФЕ - образные авторские единицы, для создания которых Б. Акунин опирается, как правило, на узуальные устойчивые выражения, преобразуя их структуру и семантику:

(42) Одним махом двух нимф услаждахом (Внеклассное чтение, с. 22);

(43) Значит, ваш подзащитный - невинная овечка, даже не подозревавшая, какого волка пригрела под своей шкуркой (Пелагия и белый бульдог, с. 234);

(44) Позвольте представиться: Ново-Араратский Сатана. Я прислан сюда взболтать тихий омут, повыпускать чертей, которые водятся здесь в изобилии (Пелагия и черный монах, с. 309);

(45) Чтобы Божье стадо с паршивыми овцами не смешивалось, существуем мы, Божьи овчарки (Пелагия и красный петух, с. 211);

(46) ...Вопль содомский и гоморский (Пелагия и белый бульдог, с. 146);

(47) У, затворники, старосветские помещики! Визит Магомета к горе! (Внеклассное чтение, с. 377);

(48) Понастроите турусов на колесах, где не надо бы, да и сами под эти колеса и угодите (Внеклассное чтение, с. 377);

(49) Хотела бы боднуть, да Бог рога не дал? А коли так, нечего было на корриду лезть, корова ты безрогая (Пелагия и черный монах, с. 407);

или используя парафразу:

(50) Запретный плод. < ..> По виду на разбивателя сердец никак не похожа, но раз интересуется неразрешенными фруктами... (Внеклассное чтение, с. 258).

Комбинированное (комбинаторное) варьирование - использование одновременно нескольких способов преобразования исходной единицы:
(51) Нечего лезть с английским уставом в русский монастырь (ФМ, т. 2, с. 53);

(52) В тихом омуте завелись нешуточные черти (Пелагия и белый бульдог, с. 157);

(53) Нет повести банальнее на свете... (Внеклассное чтение, с. 560);

(54) Для него я - обычная хорошенькая женщина (вероятно, на здешнем безрыбье) (Пелагия и черный монах, с. 287);

(55) Нечего и говорить, что с такой репутацией, как у Бубенцова, да еще на провинциальном безрыбье... (Пелагия и белый бульдог, с. 48).

В примере (51) осуществлена экспликация и лексическая мена компонентов; в (52) - экспликация и грамматическое изменение глагольного компонента; в (53) - сокращение и экспликация; в (54) и (55) - вычленение компонента из состава устойчивой фразы с его последующим распространением.

\section{Стилистические функции фразеологических единиц}

Широкое использование ФЕ в детективах Б. Акунина обусловлено рядом стилистических задач. Прежде всего фразеологизмы позволяют автору более точно воссоздать язык описываемой эпохи. По нашим наблюдениям, на долю исторического повествования приходится большая часть устаревших с точки зрения современного употребления устойчивых единиц, а также оборотов с архаичными грамматическими формами. Например:

(56) Молитвы - и той прочесть не успел. Все в руце Божьей (Алтын-толобас, с. 120);

(57) Капитану, поди, там, наверху, кажется, что он не капитан, а Господь Бог Саваоф, и не на «Севрюге» плывет, а парит на облацех (Пелагия и красный петух, с. 10);

(58) Как говорится, из свиного хвоста ермолки не сошьешь (Пелагия и красный петух, с. 297);

(59) - Послушайте, вы, врачу-исцелисясам! - грозно выкатил он глаза (Пелагия и черный монах, с. 113);

(60) Пробует Степан Трофимычу помогать, да только проку от него, как от монашки приплоду (Пелагия и белый бульдог, с. 89);

(61) Нет чтобы девушку просто обнять и поцеловать. Идиот! Сидел по-над просом, да остался с носом (Пелагия и белый бульдог, с. 148); 
(62) У царя дьяк, у дьяка хряк. Вот кто истинно империей-то правит. Никуда без него, вертлявого, не двинешься (Внеклассное чтение, с. 67);

(63) Ничего, ничего, утро вечера мудреней. Что ночью страх, то утром прах (Внеклассное чтение, с. 185);

(64) - Смесьно, - подтвердил Митя. Животики надорвешь. Ничтоже ново под солнцем. Иже возглаголет и речет: се, сие ново есть, уже бысть в вецех, бывших прежде нас (Внеклассное чтение, с. 279).

Описание приключений героев в России 90-х гг. не мыслится без соответствующей идиоматики - арготических элементов, а также жаргонных, просторечных и грубо-просторечных устойчивых оборотов, появившихся в языке перестроечного и постперестроечного периода. Например:

(65) Николас положил неприятному человеку руку на плечо, сильно стиснул пальцы и произнес нараспев: - Борзеешь, вша поднарная? У папы крысячишь? Ну, смотри, тебе жить (Алтын-толобас, c. 50);

(66) -Братан, братан... - зашептал он губами и попытался встать, но Фандорин стиснул пальцы еще сильней. - Я же не знал... В натуре не знал! Я думал, лох заморский (Алтын-толобас, с. 51);

(67) Первое чувство, которое испытал Фандорин, - не изумление, а абсурдная радость от того, что похититель кейса нашелся. Абсурдная - потому что чему тут радоваться, если от потрясения и сотрясения у человека поехали мозги (отличное идиоматическое выражение из фольклорного блокнота) и его повело в глюки (оттуда же) (Алтын-толобас, с. 87);

(68) Мы ведь с тобой не знаем, до какой степени у них на этой Либерее поехала крыша - похоже, совсем соскочила со стропил (Алтын-толобас, с. 174).

\section{Создание речевого портрета персона-} $\boldsymbol{ж} \boldsymbol{c}$ - еще одна функция фразеологии в детективах Б. Акунина.

Главному герою цикла «Приключения магистра» Николасу Фандорину, британскому гражданину с русскими корнями, свойственно владение несколькими языковыми регистрами: в зависимости от ситуации он то прибегает к жаргонной, просторечной идиоматике, то вновь возвращается к привычному для него «элитарному» языку, нередко использует англицизмы:

(69) Я леплю горбатого, - переспросил Фандорин, сделав обиженное лицо. - Вы хотите сказать, что я гоню туфту? (Алтын-толобас, с. 121);
(70) К чертовой бабушке эту историческую Родину с ее криминальными интригами и головокружительными загадками (Алтын-толобас, с. 177);

(71) План был, что называется, fool-proof («сто процентов верный») (Алтын-толобас, с. 354);

(72) - Dream, midsummer night's dream, - пробормотал Николас, уже почти не сомневаясь, что все ему снится (Алтын-толобас, с. 102).

Юная журналистка Алтын Мамаева яркая представительница молодого поколения России 90-х. Ее речь образна, экспрессивна, нередко груба, отражает все языковые особенности данного периода, а также сферы ее профессиональной деятельности:

(73) Мы не вскрываем общественные язвы и не посыпаем голову пеплом, а фиксируемся на позитиве. Чтоб люди читали журнальчик и думали: жить стало лучше, жить стало веселей (Алтынтолобас, с. 125);

(74) Надо тебя спрятать. А то оторвут башку, так я и не узнаю, что ты за хрен с горы (Алтынтолобас, с. 122);

(75) Одно из двух: или ты полный придурок, или ты мне лепишь горбатого (Алтын-толобас, с. 121).

В отличие от своего потомка, заранее изучившего тонкости современной ему русской речи, Корнелиус фон Дорн вынужден постигать особенности языка, культуры, нравов русских, только оказавшись в стране, что объясняет присутствие в его речи иноязычных вкраплений:

(76) Вот уж воистину guod licet Jovi (Алтынтолобас, с. 146);

(77) Honor primum, alia deinde (Алтын-толобac, c. 37),

в то время как транслитерации подвергаются собственно русские выражения, что помогает читателю почувствовать нюансы произношения иностранца, например:

(78) Кланяться, lomati shapku или нет? (Алтынтолобас, с. 116).

Не менее яркая языковая личность помощник Николаса Фандорина Валентин, типичный представитель современного поколения. Его речь - причудливая смесь собственно русской жаргонной, просторечной фразеологии и заимствований, устойчивых 


\section{РАЗВИТИЕ И ФУНКЦИОНИРОВАНИЕ РУССКОГО ЯЗЫКА}

оборотов, явившихся следствием контаминации русских лексических единиц и англицизмов, часто транслитерированных:

(79) - Улет, старфлайт, - мечтательно протянул Валя.

- Какой улет?

- Полный. Мужик какой-то взял и улетел. < .. > Наверно, вмазал «белого» или стэмпов нализался от них тоже крылья вырастают (Внеклассное чтение, с. 85);

(80) - Здесь гоняют лайв, - орала она на ухо Николасу в темном, битком набитом зальчике, где выступала хард-рок группа. - Сегодня жуткий дренаж, просто анкруайабль. < ..>

- Да, ник дебильный, - кивнула Валя, в свою очередь не поняв вопроса. - Давайте жать на экзит, пока не стошнило (Внеклассное чтение, с. 199);

(81) - Значит, верный супруг, да? Фэмили мэн, да? Я, как дура, ему верила, пальцем не касалась! А тут первая попавшаяся пута пальцем поманила и пожалуйста. <...> А я, значит, вам «олвиз» юзаный, да? (Внеклассное чтение, с. 211).

Многочисленные и разнообразные преобразования ФЕ помогают писателю передать особенности живой разговорной речи (речевую динамику и экспрессию, эмоциональносубъективное отношение персонажа к описываемым событиям), способствуют конкретизации значения фразеологизмов, вносят дополнительные смысловые оттенки, превращая таким образом единицу виртуальную в реально функционирующую в речи структуру.

Важная функция трансформации ФЕ в текстах Б. Акунина - придание детективному сюжету необходимого юмора. Широкие возможности фразеологии как материала для языкового каламбура не раз отмечались исследователями [Бондаренко, 2001; Мокиенко, 2012; Санникова, 2002]. «Многие фразеологизмы наделены в разной степени особой коммуникативно-прагматической целеустановкой на создание эффекта, вызывающего у слушателя / читателя удовольствие в виде смеха» [Бондаренко, 2001, с. 74].

В своих романах Б. Акунин прибегает к различным способам репрезентации смеха с помощью средств фразеологии. Например:

(82) Николас любил щегольнуть перед какойнибудь русской путешественницей безупречным московским выговором и знанием современной идиоматики. Неизменное впечатление на барышень производил прекрасно освоенный трюк: двухметровый лондонец, не по-родному учтивый, с дурацкой приклеенной улыбкой... вдруг говорил: «Милая, не завалиться ли нам в Челси? Там нынче улетная тусовка» (Алтын-толобас, с. 9).

Здесь языковой каламбур основан на употреблении жаргонной идиоматики в нетипичной для нее ситуации.

(83) Когда-то в юности Ник Фандорин неплохо играл в бейсбол, даже был лучшим хиттером школьной команды. Конечно, он не надеялся перефехтовать шустрого гения, но появилась одна идея - дикая, даже полоумная. Шанс она давала самый крохотный. Но утопающий ведь хватается за соломинку, а тут все-таки бита. Прочная, ухватистая, тяжелая (ФМ, т. 1, с. 223).

В данном фрагменте происходит обыгрывание значения устойчивой фразы за счет употребления лексемы «бита» со значением «спортивный снаряд из твердого материала для игры в лапту, бейсбол и пр.», антонимичной компоненту «соломинка» - «нечто малое и часто бесполезное для спасения».

(84) Столичные люди, те ничего, известия о конце света не испугались, только навострили уши и ближе к монаху придвинулись, а вот судейский уборщик... тот от страшного крика на месте обмер, орудие свое уронил, закрестился. А предвестник Апокалипсиса членораздельно говорить от тоски и ужаса более не мог - затрясся всем телом, и по мучнистому, обросшему бородой лицу покатились слезы (Пелагия и черный монах, с. 5).

Согласно христианским представлениям, предвестники Апокалипсиса - Чума, Война, Голод и Смерть - наделены силой сеять хаос и разрушение в мире и сами внушают ужас. Употребление этого выражения применительно к смертному человеку, испытывающему при этом огромное потрясение, и создает необходимый комический эффект.

(85) Могу похвастаться: схиигумен (у него по краю куколя белая кайма) удостоил меня своим святейшим вниманием - клюкой погрозил, чтоб близко не подплывал (Пелагия и черный монах, с. 59).

Устойчивое выражение «уделить внимание» со значением «проявить благосклонность, заботу и пр.» употребляется, как пра- 
T.B. Сафонова. Функционирование фразеологических единиц в детективной прозе Б. Акунина

вило, в ситуациях, имеющих благоприятный исход для участников событий. В данном контексте используется нетипичная для оборота конкретизация его значения.

(86) - Хорошо бы мы с тобой смотрелись, стал описывать преосвященный. Несемся сломя голову по Большой Дворянской: рясы подобрали, у меня борода по ветру веником, у тебя патлы рыжие полощутся (Пелагия и черный монах, с. 179).

Здесь также посредством текстуального окружения конкретизируется семантика фразеологизма, создается более зримая картина событий, что не может не вызвать улыбку у читателя.

(87) Все свои многочисленные успехи на архипастырском поприще Митрофаний приписывал Господу. $<. . .>$ Но на самом деле больше руководствовался максимой «На Бога надейся, а сам не плошай», и, надо сказать, плошал он редко, не обременял Господа лишними заботами (Пелагия и черный монах, с. 28).

В данном случае языковой каламбур строится на употреблении в пределах одного фрагмента пословицы и ее отдельных компонентов с нетипичными для них распространителями, что переводит их пословичную семантику из религиозного в иной, бытовой план.

\section{Заключение}

Таким образом, фразеологическая составляющая детективов Б. Акунина масштабна и представлена разными типами устойчивых единиц, как в словарной форме, так и в преобразованном виде. Способы трансформации фразеологизмов различны: затрагивают как семантику, так и форму единиц; в результате трансформаций нередко возникают окказиональные обороты. Широкое использование в детективных романах фразеологического богатства русского языка в целом позволяет писателю реализовать ряд художественных задач, придает языку его произведений яркость, образность, оригинальность, способствуя созданию неповторимого стиля Б. Акунина.

\section{СПИСОК ЛИТЕРАТУРЫ}

Амусин М., 2009. Чем сердце успокоится. Заметки о серьезной и массовой литературе в России на рубеже веков // Вопросы литературы. № 3. C. 5-45.

Бондаренко В. Т., 2001. О смеховой функции русской фразеологии // Русский язык в школе. № 3. C. 74-76.

Бондаренко В. Т., 2011. Устойчивые фразы в русской речи. Тула : Изд-во ТГПУ. 153 с.

Ермакова Е. Н., Прокопова М. В., 2013. Трансформация фразеологических единиц как языковая стратегия массовой литературы (на материале цикла Б. Акунина «Нефритовые четки») // Вестник Челябинского государственного педагогического университета. № 3. С. 271-281.

Максимова Н. И., Корнилова Л. Н., 2018. Фразеологизм как компонент идиостиля Акунина-беллетриста и Чхартишвили-публициста в книге «Кладбищенские истории» // Язык. Культуpa. Коммуникации. № 2. URL: https://journals. susu.ru/lcc/article/view/652/853 (дата обращения: 26.08.2019).

Марусенко Н. М., Скребцова Т. Г., 2013. Типичное и нетипичное в структуре детектива // Мир русского слова. № 4. С. 74-79.

Мокиенко В. М., 2012. Фразеология и языковая игра: динамика формы и смысла // Ученые записки Таврического национального университета им. В.И. Вернадского. Серия: Филология. Социальные коммуникации. Т. 25 (64), № 2, ч. 1. С. $100-109$.

Осьмухина О. Ю., 2016. Специфика авторской стратегии Бориса Акунина: жанровый аспект // История русского литературного процесса $\mathrm{XI}-\mathrm{XX}$ вв. и закономерности его развития на современном этапе : электрон. сб. ст. по материалам III Всерос. (с междунар. участием) науч.-практ. конф. (г. Чебоксары, 20 нояб. 2015 г.). Чебоксары : Чуваш. гос. пед. ун-т им. И.Я. Яковлева, 2016. С. 133-139.

Санникова В. 3., 2002. Русский язык в зеркале языковой игры. М. : Яз. слав. культуры. 552 с.

Сафонова С. С., 2008. Функционирование фразеомоделей с семантикой обусловленности в языке романов Б. Акунина // Вестник Татарского государственного гуманитарно-педагогического университета. № 3 (14). С. 71-74.

Снигирева Т. А., Подчиненов А. В., Снигирев А. В., 2017. Борис Акунин и его игровой мир. СПб. : Алетейя. 178 с.

\section{ИСТОЧНИКИ}

Акунин Б. Алтын-толобас. М. : АСТ, 2017. 384 с. Акунин Б. Внеклассное чтение. М. : АСТ, 2017. 576 с. Акунин Б. Пелагия и белый бульдог. М. : АСТ, 2014. 319 c. 
Акунин Б. Пелагия и красный петух. М. : АСТ, $2014.511 \mathrm{c}$.

Акунин Б. Пелагия и черный монах. М. : АСТ, $2015.416 \mathrm{c}$.

Акунин Б. Сокол и Ласточка. М. : АСТ, 2016. 447 с. Акунин Б. Ф. М. : в 2 т. М. : АСТ, 2017. Т. 1.319 с. ; T. $2.285 \mathrm{c}$.

\section{REFERENCES}

Amusin M., 2009. Chem serdtse uspokoitsya. Zametki o seryeznoy i massovoy literature $v$ Rossii na rubezhe vekov [How the Heart Calms Down. Notes on Serious and Popular Literature in Russia at the Turn of the Century]. Voprosy literatury, no. 3, pp. 5-45.

Bondarenko V.T., 2001. O smekhovoy funktsii russkoy frazeologii [On Humorous Function of Russian Phraseology]. Russkiy yazyk v shkole [Russian Language at School], no. 3, pp. 74-76.

Bondarenko V.T., 2011. Ustoychivye frazy v russkoy rechi [Set Phrases in Russian Speech]. Tula, Izd-vo TGPU. 153 p.

Ermakova E.N., Prokopova M.V., 2013. Transformatsiya frazeologicheskikh edinits kak yazykovaya strategiya massovoy literatury (na materiale tsikla B. Akunina «Nefritovye chetki») [Phraseological Units Transformation As a Language Strategy of Mass Literature (On the Basis of "Jade Beads" by B.Akunin)]. Vestnik Chelyabinskogo gosudarstvennogo pedagogicheskogo universiteta [Herald of Chelyabinsk State Pedagogical University], no. 3, pp. 271-281.

Maksimova N.I., Kornilova L.N., 2018. Frazeologizm kak komponent idiostilya Akunina-belletrista i Chkhartishvili-publitsista v knige «Kladbishchenskie istorii» [Phraseological Unit as a Component of Boris Akunin's and Grigory Chkhartishvili's Individual in Book "Cemetery Tales"]. Yazyk. Kultura. Kommunikatsii [Language. Culture. Communication], no. 2. URL: https://journals.susu.ru/lcc/article/view/652/853 (Accessed 26 August 2019).

Marusenko N.M., Skrebtsova T.G., 2013. Tipichnoe i netipichnoe v strukture detektiva [Typical and Non-typical in the Structure of Detective Stories]. Mir russkogo slova [The world of Russian word], no. 4, pp. 74-79.

Mokienko V.M., 2012. Frazeologiya i yazykovaya igra: dinamika formy i smysla [Phraseology and Language Game: The Dynamics of Form and Meaning]. Uchenye zapiski Tavricheskogo natsionalnogo universiteta im. V.I. Vernadskogo. Seriya: Filologiya. Sotsialnye kommunikatsii, vol. 25 (64), no. 2, part 1, pp. 100-109.
Osmukhina O.Yu., 2016. Spetsifika avtorskoy strategii Borisa Akunina: zhanrovyy aspekt [Specifics of the Author's Strategy of Boris Akunin: Genre Aspect]. Istoriya russkogo literaturnogo protsessa $X I-X X$ vv. $i$ zakonomernosti ego razvitiya na sovremennom etape: elektron. $s b$. st. po materialam III Vseros. (s mezhdunar. uchastiem) nauch.-prakt. konf. (g. Cheboksary, 20 noyab. 2015 g.) [The History of the Russian Literary Process of the $11^{\text {th }}-20^{\text {th }} \mathrm{c}$. and Patterns of Its Development at the Present Stage: Electronic Collection of Articles based of the Proceedings of the $3^{\text {rd }}$ All-Russian (With International Participation) Scientific and Practical Conference (Cheboksary, November 20, 2015). Cheboksary, Chuvashskiy gosudarstvennyy pedagogicheskiy universitet im. I.Ya. Yakovleva, pp. 133-139.

Sannikova V.Z., 2002.Russkiy yazyk v zerkale yazykovoy igry [Russian Language in the Mirror of the Language Game]. Moscow, Yazyki slavyanskoy kultury, 2002. 552 p.

Safonova S.S., 2008. Funktsionirovanie frazeomodeley s semantikoy obuslovlennosti v yazyke romanov B. Akunina [The Functioning of the Phraseological Models with Conditional Semantics in the Language of B. Akunin's Novels]. Vestnik Tatarskogo gosudarstvennogo gumanitarno-pedagogicheskogo universiteta, no. 3 (14), pp. 71-74.

Snigireva T.A., Podchinenov A.V., Snigirev A.V., 2017. Boris Akunin i ego igrovoy mir [Boris Akunin and His Game World]. Saint Petersburg, Aleteya Publ. 178 p.

\section{SOURCES}

Akunin B. Altyn-tolobas [Altyn-Tolobas]. Moscow, AST Publ., 2017. 384 p.

Akunin B. Vneklassnoe chtenie [Extracurricular Reading]. Moscow, AST Publ., 2017. 576 p.

Akunin B. Pelagiya i belyy buldog [Pelagia and the White Bulldog]. Moscow, AST Publ., 2014. $319 \mathrm{p}$.

Akunin B. Pelagiya i krasnyy petukh [Pelagia and the Red Rooster]. Moscow, AST Publ., 2014. $511 \mathrm{p}$.

Akunin B. Pelagiya i chernyy monakh [Pelagia and the Black Monk]. Moscow, AST Publ., 2015. 416 p.

Akunin B. Sokol $i$ Lastochka [The Falcon and the Swallow]. Moscow, AST Publ., 2016. 447 p.

Akunin B. F.M. Moscow, AST Publ., 2017, Vol. 1. 319 p. Vol. 2. 285 p. 
T.B. Сафонова. Функционирование фразеологических единиц в детективной прозе Б. Акунина

\section{Information about the Author}

Tatyana V. Safonova, Candidate of Sciences (Philology), Associate Professor, Russian Language and Literature Department, Tula State Lev Tolstoy Pedagogical University, Prosp. Lenina, 125, 300026 Tula, Russia, safonova76@mail.ru, https://orcid.org/0000-0001-8871-2069

\section{Информация об авторе}

Татьяна Владимировна Сафонова, кандидат филологических наук, доцент кафедры русского языка и литературы, Тульский государственный педагогический университет им. Л.Н. Толстого, просп. Ленина, 125, 300026 г. Тула, Россия, safonova76@mail.ru, https://orcid.org/0000-0001-8871-2069 